\title{
Geometrical Nonlinear Analysis for Multi-Parameters of Four Tower Cable-Stayed Bridge Based on The Bar Element Model
}

\author{
Feng Xion-Hui and Zhu Zi-Qiang \\ School of Geosciences an Info-Physics, \\ Central South University, \\ Changsha, Hunan 410083, P.R. China;
}

\author{
He Xian-Qi* \\ Hunan Provincial Communications Planning Survey \\ Changsha, Hunan 410008, P.R. China \\ hexqi666@hotmail.com
}

$$
E_{e q}=\frac{E_{0}}{1+\left[(\gamma l)^{2} / 12 \sigma^{3}\right] E_{0}}
$$

\begin{abstract}
Based on the nonlinear theory of cable-stayed bridge, nonlinear effects- cable sag, beam column effect, large displacement are calculated accurately using element geometric stiffness matrix, CR formulation, bar unit, Ernst formula and the catenary equation. Nonlinear analysis is applied on the study of cable force, the stress in main girder, pylon stress and tower deviation of the four towers cable-stayed bridge. The calculation results considering nonlinear effect is compared with which nonlinear effect is not considered under completion state. Results show that the geometric nonlinearity effect on the cable force is $0.09 \sim 1.04 \%$; the effect on cumulative vertical displacement is -5 $\sim 5 \mathrm{~mm}$; the effect on the lower edge stress of main girder is $0.5 \sim$ $1.5 \%$; the effects on the higher edge stress of main girder is 0 $0.5 \%$. The effect on the lower edge stress of girder is significantly higher than the upper edge. The effect on the stress of tower is $0.1 \sim 0.1 \mathrm{MPa}$; the effect on horizontal deviation difference at the top of tower is $1.4 \% \sim 3.1 \%$. Results show that the geometric nonlinearity has a certain effect on the state of bridge, the effects of geometric nonlinearity should be considered in design and construction control calculation.
\end{abstract}

Keywords - cable-stayed bridge; nonlinear; cable; girder; CR formulation

\section{GeOMEtrical NonlineAr TheORY FOR CABLE-STAyed BRIDGE}

There are three aspects of geometric nonlinearity [1-5]: (1) Cable sag; (2) beams effect; (3) large displacement. Considering the geometrical nonlinear problems on bridge, the treatment of the three nonlinear factors is discussed as following.

\section{A. Nonlinear Effects Generated by Cable Sag}

Axial stiffness of stay cables change with sag, in turn sag depends on the tension of stay cable, there is a clear nonlinearity between tension and distortion of stay cable $[4,5]$. If nonlinearity is considered, stiffness can be described by equivalent elastic modulus and equivalent elastic modulus of stay cable can be described as following (Ernst formula):
Where $E_{e q}$ is equivalent elastic modulus, $E_{0}$ is the elastic modulus of cable, $\sigma$ is the tensile stress, $l$ is the length of stay cable, $\gamma$ is the weight of per unit length of stay cable.

\section{B. Beam-Column Coupling Effect [4-12]}

Under the tension of cable, main girders, towers and other components receive bending moments and axial force action simultaneously. Under this situation, the material that satisfies Hooke's Law also presents non-linear characteristics. Lateral deflection of the component under axial force can cause additional moment and, in turn, the moment has effect on the size of the axial stiffness. The method based on the finite element discretization and used to handle beam-column coupling effect nonlinearity of cable-stayed bridge is stabilizing Function.

The stabilizing function of axial rod is [4]:

$$
\begin{gathered}
S_{1}=\frac{u^{3} \sinh u}{12(2-\cosh u+u \sinh u)}=\frac{u^{3} \sinh u}{12 R_{t}} \\
S_{2}=\frac{u^{3}(\cosh u-1)}{6(2-\cosh u+u \sinh u)}=\frac{u^{3}(\cosh u-1)}{6 \mathrm{R}_{t}}
\end{gathered}
$$

$$
\begin{gathered}
S_{3}=\frac{u(u \cosh u-\sinh u)}{4(2-\cosh u+u \sinh u)}=\frac{u(u \cosh u-\sinh u)}{4 R_{t}} \\
S_{4}=\frac{u(\sinh u-u)}{2(2-\cosh u+u \sinh u)}=\frac{u(\sinh u-u)}{2 R_{t}}
\end{gathered}
$$




$$
S_{5}=1 /\left(1-\frac{E A R_{t m}}{4 F^{3} L^{2}}\right)
$$

where, $S_{1-5}$ is stabilizing function, $u=l \sqrt{F / E I}$

$\mathrm{F}$ is the axial force, EI is flexural rigidity of the component, 1 is the length of the cable, $\mathrm{A}$ is cross-section of cable.

$$
R_{t}=2-\cos h u+u \sin h u
$$

$$
\begin{aligned}
& R_{t m}=u \times\left(M_{i}^{2}+M_{j}^{2}\right) \times\left(\operatorname{coth} u+u \operatorname{cosech}{ }^{2} u\right) \\
& -2\left(M_{i}+M_{j}\right)^{2}+M_{i} M_{j} \times(1+u \cot h u) \times 2 u \operatorname{cosech} u
\end{aligned}
$$

\section{$M_{l}, M_{j}$ is the moment of rod end.}

\section{Large Deformation Effect}

The geometry position of the superstructure of cable-stayed bridge changes significantly under normal loads, and the coordinates of a structural node changes significantly. The length, angle and other geometrical characteristics of each unit also change significantly, so, the balance equation present nonlinear relationship.

In this case, load and displacement is no longer a linear relationship, and there is no longer a proportional relationship exists between the internal forces and external load, thus additional stress which is not proportional to load increment is caused. Additional stress can be calculated using successive approximation method $[4,5,15,16]$.

\section{NUMERICAL SOLUTION FOR GEOMETRIC NONLINEARITY}

Considering that geometry nonlinear finite element equation is the equilibrium equations which based on configuration caused by structure deformation, and the structural stiffness matrix is a function of the demand displacement, so, only successive approximation numerical method can be used.

Numerical methods currently used are: load increment method, iterative method and mixing [12-14], load increment method and mixing method with drag coordinates is highlights here.

\section{A. Load Increment Method}

Load incremental approach is the method that put the nonlinear cable into transient linear segments. Equivalent static equilibrium equations and the displacement calculation formula of the $\mathrm{i}$ increment process is described as follows:

$$
\begin{gathered}
{[K]_{i}\{\Delta \delta\}_{i+1}=\{\Delta P\}_{i}} \\
\{\delta\}_{i+t}=\{\delta\}_{i}+\{\Delta \delta\}_{i+1}
\end{gathered}
$$

where, $[\mathrm{K}]_{\mathrm{i}}$ is a starting structural rigidity of the i-class load increment. $\{\Delta \delta\}_{\mathrm{i}+1}$ is the node displacement increment caused by $\mathrm{i}$-class load increment; $\{\Delta \mathrm{P}\}_{\mathrm{i}}$ is the $\mathrm{i}$-class load increment; $\{\Delta \delta\}_{\mathrm{i}},\{\Delta \delta\}_{\mathrm{i}+1}$ is the beginning and end nodal displacements of i-class load.

\section{B. Mixing Method with Drag Coordinates [4]}

"Drag the coordinate system" based on U.L , also known as $\mathrm{CR}$ formation can be used to solve the geometric nonlinear problem caused by large displacement effects. Single rigid of the deformed component can be describe by $\left[K_{T}^{t}\right]^{e}$, if $\left[K_{T}\right]^{e}=\left[K_{T}\left(\{\delta\}^{e}\right)\right]^{e}$ ( $\delta$ is displacement $)$, the nodal force $\{F\}^{e}$ can be describe by nodal displacement: $\{F\}^{e}=\left[K_{T}\right]^{e}\{\delta\}^{e}$, and the force action on node by deformed unit is:

$$
\left\{F_{r}\right\}=-\sum_{e=1}^{n_{e}}\{F\}^{e}
$$

$$
\{\Delta F\}=\{F\}+\left\{F_{r}\right\}=\{F\}-\sum_{e=1}^{n_{e}}\{F\}^{e}
$$

The second approximation of the displacement can be calculated by acting the unbalance force on each node, and repeating the process until $\{\Delta \mathrm{F}\} \approx 0$.

\section{CAlculation Model}

Chishi Bridge is a large bridge which belonged to Rucheng to Chenzhou section of the Xiamen to Chengdu highway. The bridge is a four towers cable-stayed bridge with double cable planes. The spanning structure of which is $165 \mathrm{~m}+3 \times 380 \mathrm{~m}$ $+165 \mathrm{~m}$. Each tower of bridge is arranged 24 pairs of cable, the cable is arranged into fan-shaped in longitudinal direction [17$19]$.

The bridge is divided into 201 sections, and a section of the main girder is a single box with four rooms, which is $3.2 \mathrm{~m}$ high in the center, is $27.5 \mathrm{~m}$ width at the top of girder.

Plane linkage model is used for calculation, and computing grid is shown in Fig. 1. Conventional beam element is used to simulate the main beam and girder element, and cable-stayed cable is simulated by cable element.

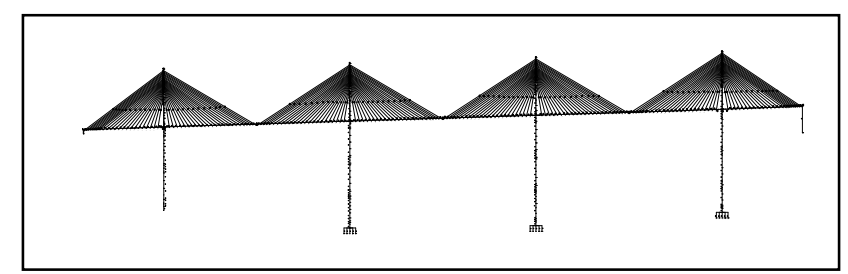

Fig. 1. Computational grid of cable-stayed bridge.

The bridge is divided into 820 units and 553 nodes among which 1 228 are the elements of the main beam and 229 424 are cable units, 425 686 are the elements of the main tower. Concrete density of the tower is $26 \mathrm{kN} / \mathrm{m}^{3}$, the secondary dead load is linear load which is $66.6 \mathrm{kN} / \mathrm{m}$. The load of the 
diaphragm of the main beam is acted in form of nodal or nonnodal. Typical geometric characteristics of girders are shown in Table I.

TABLE I. THE GEOMETRIC CHARACTERISTICS OF GIRDER

\begin{tabular}{|c|c|c|c|c|}
\hline item & $\mathrm{A}\left(\mathrm{m}^{2}\right)$ & $\mathrm{I}\left(\mathrm{m}^{4}\right)$ & $\begin{array}{c}\mathrm{W}_{\text {below }} \\
\left(\mathrm{m}^{3}\right)\end{array}$ & $\begin{array}{c}\mathrm{W}_{\text {up }} \\
\left(\mathrm{m}^{3}\right)\end{array}$ \\
\hline IIIsection & 22.333 & 29.066 & 16.369 & 20.408 \\
\hline IV section & 40.303 & 44.768 & 25.916 & 30.401 \\
\hline IV section & 42.599 & 45.533 & 26.500 & 30.728 \\
\hline Solid section & 74.235 & 54.059 & 32.465 & 35.222 \\
\hline
\end{tabular}

\section{Calculation Under DeAd Load State}

\section{A. Cable Force}

Cable force caused by each tension of construction state and dead Load state is show in Fig. 2, 3.

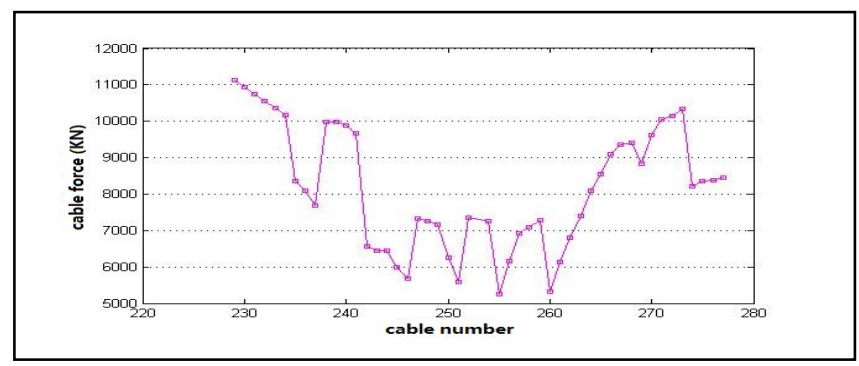

Fig. 2. Cable force of $5 \#$ tower.

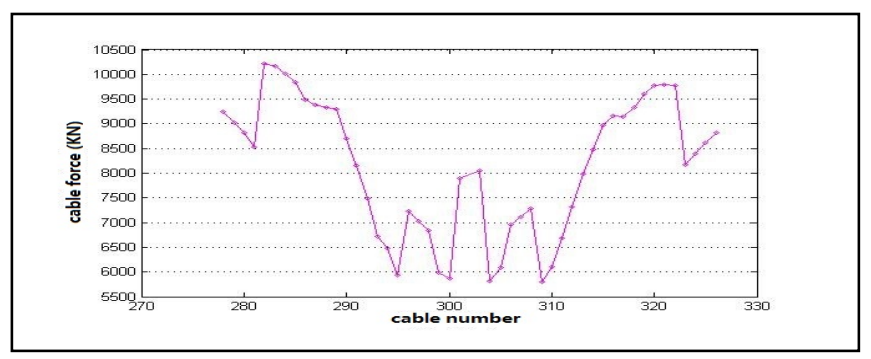

Fig. 3. Cable force of $6 \#$ tower.

\section{B. Internal Force and Stress of Girder}

The result of internal force and stress of girder is shown in Fig. 4, 5 .

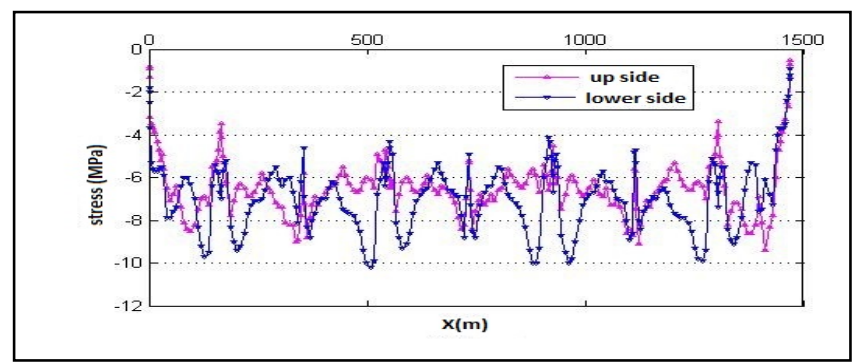

Fig. 4. Girder stresses under completion state.

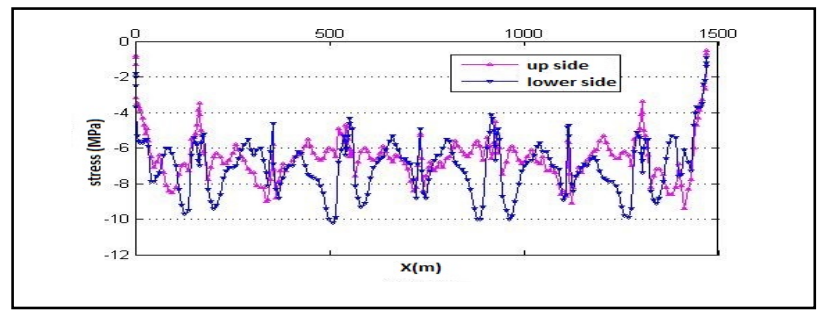

Fig. 5. Axial force of girder under completion state.

\section{Cumulative Displacement of Main Beam}

Cumulative displacement for the main beam under dead load stage is shown in Fig. 6. Cumulative displacement for the left of the main beam under dead load is $259.4 \mathrm{~mm}$, on the other side is $-263.6 \mathrm{~mm}$

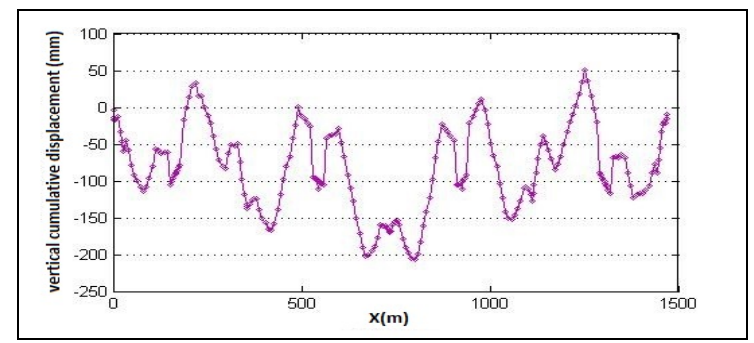

Fig. 6. The cumulative vertical displacement of girder under dead load of completion state.

\section{Stress and Internal force of Main Tower}

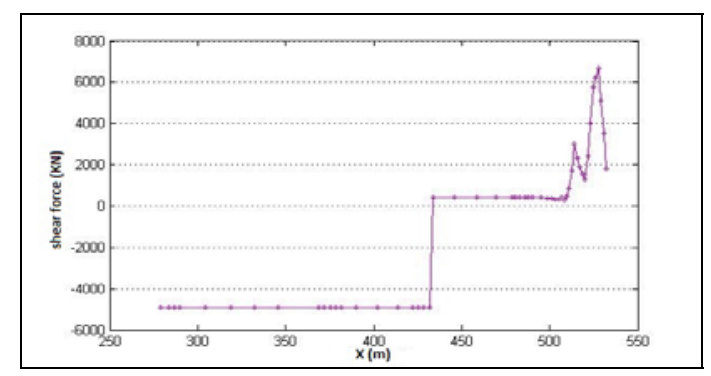

(a) The sheer force of tower.

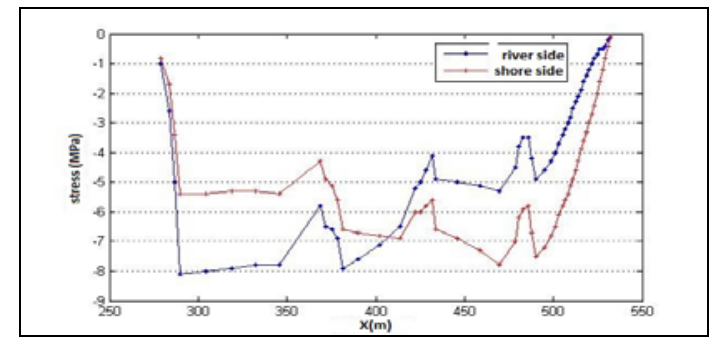

(b) The stress of tower.

Fig. 7. The calculation results of stress and internal force of tower 5 under dead load. 
Stress, internal force of the fifth tower under dead load is shown in Fig. 7.

It is concluded that distribution of cable force under dead load is reasonable; the moments of the beam is small, the force act on the main beam is reasonable and bridge beam is safety.

\section{ANALYSIS OF GEOMETRIC NONLINEARITY}

The effect of Initial internal force on stiffness for the unit can be considered by introducing geometric stiffness matrix, when geometric nonlinearity is analysis.

The impact of nonlinearity on large displacement can be analysis by establishing equilibrium equation using $\mathrm{CR}$ formulation method.

The change of stiffness per unit for cable element caused by the cable sag can be approximated by rod unit and the sag effect can be approximated by equivalent modulus method through introducing Ernst formula in the linear calculation. In addition, sag effect can be calculated accurately using catenary equation in the nonlinear calculation.

\section{A. The effects of Geometric Nonlinearity on Cable Force Under Dead Load}

The effect of geometric nonlinearity on cable force under dead load for fifth tower is shown in Fig. 8. The difference of cable force is the value of which the force considering nonlinearity subtracts the linear force under dead load. The negative cable number indicates the left side and positive number indicates the right side.

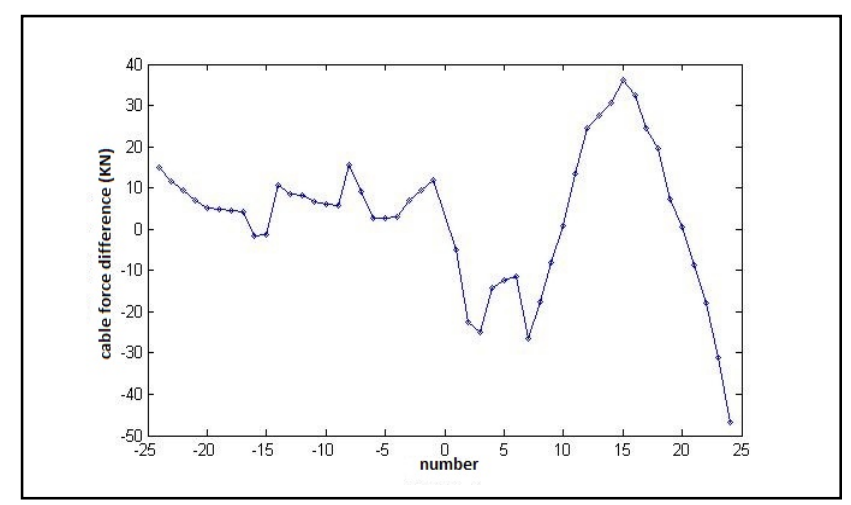

Fig. 8. Effect on cable force of 5\#tower under completion state.

\section{B. The Effects of Geometric Nonlinearity on Vertical Cumulative Displacement Under Dead Load}

The effects of geometric nonlinearity on vertical cumulative displacement under dead load are shown in Fig. 9. The difference of displacement is the value that the cumulative displacement considering nonlinearity subtracts the linear cumulative displacement under dead load.

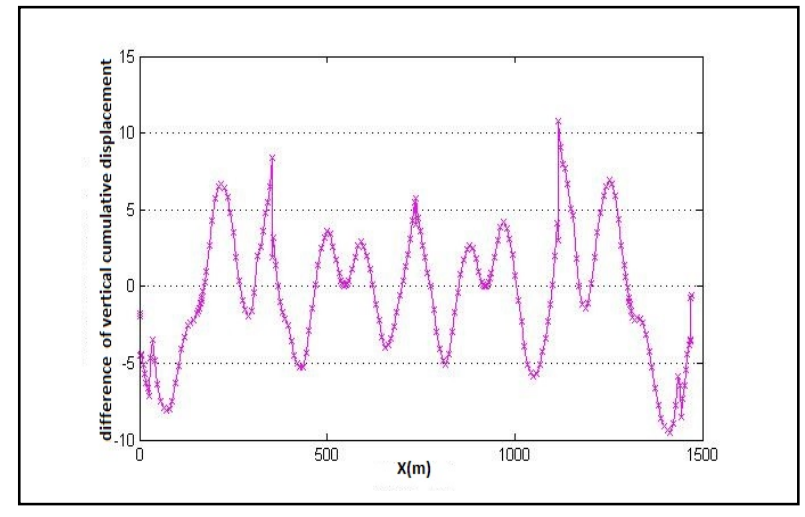

Fig. 9. The effect of geometrical nonlinearity on cumulative vertical displacement under completion state.

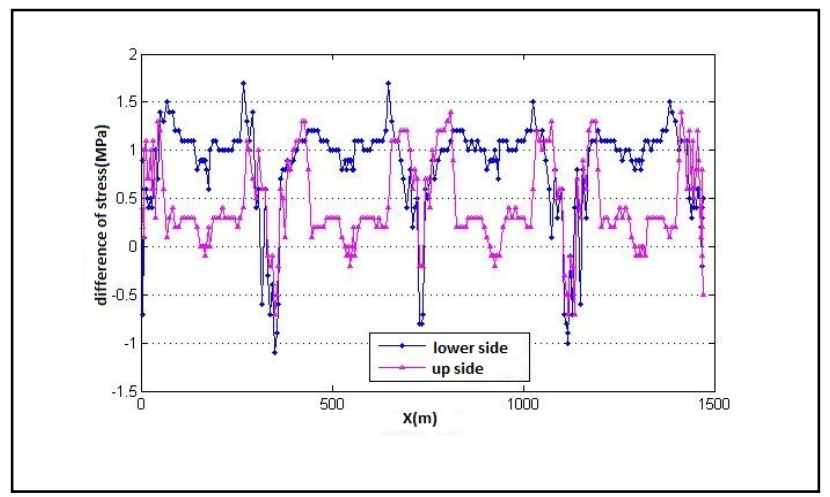

Fig. 10. The effect of geometrical nonlinearity on the stress of girder under completion state.

\section{The Effects of Geometric Nonlinearity on the Stress of Girder Under Dead Load}

The effect of geometric nonlinearity on vertical cumulative displacement under dead load is shown in Fig. 10. The difference of stress is the value that the stress considering nonlinearity subtracts the linear stress under dead load.

\section{The Effects of Geometric Nonlinearity on Stress and Deviation of Tower Under Dead Load}

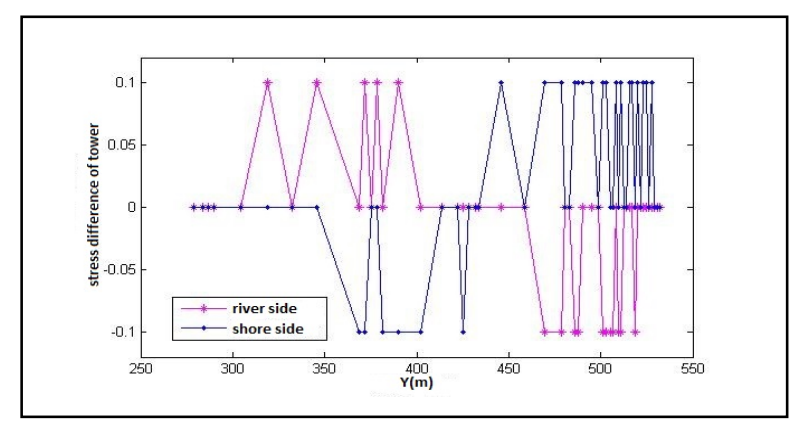

Fig. 11. The effect of geometrical nonlinearity on the stress of girder under completion state. 
The effect of geometric nonlinearity on the stress of seventh and eighth tower under dead load is no longer listed list detail.

The effect difference percentage of geometric nonlinearity on deviation at the top of the fifth tower under dead load is $2.0 \%$ and it is $1.4 \%$ for the sixth tower, $3.1 \%$ for seventh tower, $2.1 \%$ for eighth tower.

\section{CONCLUSIONS AND SUGGESTION}

Geometric nonlinear effects are as follows according to the calculations above:

A. The cumulative displacement of the left side of main girder under dead load is $259.4 \mathrm{~mm}$ and it is $-263.6 \mathrm{~mm}$ at right side.

B. The absolute value of the effect on cable force is $0.09 \sim$ $1.04 \%$, the main range is $0.3 \sim 0.6 \%$;

C. The effect range on cumulative displacement is $-5 \sim 5 \mathrm{~mm}$.

$D$. The effect range for lower side of main girder is $0.5 \sim 1.5 \%$, it locate at $1 \%$ mainly and the maxim is $1.7 \%$. The effect range for up side of main girder is $0 \sim 0.5 \%$, and the maxim is $1.4 \%$. The effect on lower side of girder is larger than value of the up side obviously.

$E$. The effect on stress of tower is $-0.1 \sim 0.1 \mathrm{MPa}$.

The effect difference percentage of geometric nonlinearity on deviation at top of the fifth tower under dead load is $2.0 \%$ and it is $1.4 \%$ for the sixth tower, $3.1 \%$ for the seventh tower, $2.1 \%$ for eighth tower.

Through the calculation analysis, geometric nonlinearity has some influence on the bridge, and it is recommended that nonlinear effects should be considered in design and calculation of construction control.

\section{REFERENCES}

[1] P.H. Wang, H.T. Lin, and T.Y. Tang, "Study on nonlinear analysis of a highly redundant cable-stayed bridge." Comput. Struct., vol. 80, issue 2 pp. 165-182, 2002.

[2] P.H. Wang, T.Y. Tang, and H.N. Zheng. "Analysis of cable-stayed bridges during construction by cantilever method." Comput Struct., vol. 82,issue 4-5, pp. 329-346, 2004.

[3] L.I. Qiao, Yang Xing-Wang, and P.U. Yi-Zhi, "effect of geometric nonlinearity on deformation of extra-long-span cable-stayed bridge", J. Southwest Jiaotong U., vol. 42, no. 2, pp. 143-147, 2007.

[4] H. Zhang. "Study on the Geometric Nolinearity and Construction Control of Long Span Cable-stayed Bridge" Doctoral dissertation, wuhan: Huazhong University of Science \& Technology, pp.23-36, 2008

[5] C.J. Pang, "Geometric nonlinear analysis of long span multipylon cablestayed bridge" Master thesis, Chengdu: southwest jiaotong university, pp. $10-19,2010$

[6] C.S. Chen. "Theory an application study of meticulous analysis of geometrical nolinearity of Super long span cable stayed-bridge under construction." Doctoral thesis, Cahgnsha: central south university, 2007.

[7] M.Y. Liu, and J.J. Nie, "Analysis on the Composite Girder Cable-stayed Bridge with Three Towers by Geometrical Nonlinear Refined Simulation", J. Huazhong University of Science \& Technology, vol. 27, no. 3, pp. 1-5. 2010.

[8] L.M. Chen, and C.B. Long, "Research on self adaptive construction control method of cable-stayed bridge considering geometric nonlinearity", Hunan. Communication. Sci. Technol., vol. 01, pp. 62-66, 2014.

[9] R.G. Liu, B. Guo, D.S. Cai, and M. Zhu, "CFRP cable-stayed bridge's dynamic properties with geometric nonlinear effect considered.", J. Chang'an U. (natural science edition), vol. 02, pp. 59-64, 2014.

[10] X. Li. "Analysis on the nonlinear behavior of long-span cable-stayed bridges considering construction process.", Master thesis, Shanghai: Southwest Jiaotong U., pp.5-7,2013

[11] T.B. Chen. "Analysis of Long-Span Cable-Stayed Bridges Using Geometrical Nonlinear Finite Element Method." Tech. Econ. Areas Commun. vol. 04, pp. 37-38, 2009.

[12] Hunan Provincial Communications Planning Survey.Chishi super bridge construction drawing design,pp.22-53, 2009 